\title{
Obtención y Evaluación de Destilados a partir de Mostos Fermentados de Higos (Ficus carica L) Secos y Rehidratados de Tacna
}

\section{Obtainment and Evaluation of Distils from Fermented Musts of Sun Dried and Rehydrated Figs (Ficus carica L) in Tacna}

\author{
' Samuel Román Cerro Ruiz
}

\begin{abstract}
RESUMEN:
Este trabajo tuvo como finalidad la evaluación organoléptica con base en escala hedónica de tres destilados obtenidos a partir de higos (Ficus carica L.) deshidratados de la variedad Black mission, teniendo como factor variable la proporción de fruta: agua (D1-1:3, D2-1:4 y D3-1:5) mientras que, las variables fijas fueron el tiempo de rehidratación y maceración. La fermentación fue llevada a cabo en tres etapas consecutivas, siendo éstas de 3, 5 y 10 dias. El contenido de sólidos solubles, azucares reductores, acidez total, grado alcohólico y rendimiento del vino base fueron de 30, 20, 8.32, 22.6, 69.1\% para D1, 21.5.8.2.7.1.24.1, 64.9\% para D2 y 17, 5.7.6.2, 24.4, 67.12\% para D3 respectivamente. Las muestras fueron destiladas ohteniéndose contenidos alcohólicos de 38\% (D1), 40\% (D2) y 40.5\% (D3) (v/v), asimismo la acidez total presentó valores de 17.7, 9.8 y 10.4 mg/L. respectivamente. Finalmente, se evaluaron los tres destilados con un panel de jurados semientrenados resultando con mayor preferencia la muestra D3 (7.68 puntos:- bueno), mientras que las muestras D1 y D2 fueron calificadas como regulares (6.68 y 6.37 ).
\end{abstract}

Palabras clave: higos deshidratados, destilados, vino base, análisis sensorial, escala hedónica

\section{ABSTRACT:}

The aim of this job was to perform a sensorial evaluation on three beverages obtained from distillation of cuvees using dehydrated figs (Ficus carica L.) type Black mission. A Hedonic scale was used to find out juries' preferences. The mobile factor was the proportion of fruit: water (DI1:3. D2-1:4 y D3-1:5) used for making cuvees, while, rehydration and maceration times were controlled. Fermentation was performed in three consecutive stages of 3, 5 and 10 days, obtaining cuvees yields of $69.1 \%$ for D1, $64.9 \%$ for D2 y $67.12 \%$ for D3. Soluble solids, reducing sugar content, total acidity and alcoholic degree were 30, 20, 8.32 y 22.6 for D1, 21.5, 8.2, 7.1 y 24. I for D2 y 17. 5.7, 6.2 y 24.7 for D3 respectively. Once that distillation was performed, alcoholic degree values were measured obtaining 38\% (D1), 40\% (D2) y 40.5\% (D3) (v/v). Total acetic acidity content was 17.7 (D1), 9.8 (D2) y 10.4 (D3) $\mathrm{mg} / \mathrm{L}$ values. Finally, with a semi-trained panel, the samples were evaluated resulting D3 as the best in preference with 7.68 good, while. D1 and D2 were qualified as regular (6,68 and 6,37 points).

Keywords: spirits, dehydrated figs, sensorial analysis, cuvees, hedonic scale. \footnotetext{
'Master of Science con Mención en Gestión Empresarial, Ingeniero en Industrias Alimentarias. Facultad de Ciencias Agropecuarias, Universidad
Nacional Jorge Basadre Grohmann.
} 


\section{INTRODUCCIÓN}

Desde el siglo XVIII, en los valles de Vitor y Siguas en Arequipa y de Moquegua, se han venido elaborando y consumiendo algunas bebidas a base de higos secos, algunas como refresco y otras como bebidas espirituosas de baja graduación alcohólica (de 5 a 6 grados), conocidos como "Chimbangos de 2 y 3 higos", como un indicativo de las veces que se fermentaban. Pero también se elaboraban aguardientes de higos secos de aproximadamente 19 a 20 grados alcohólicos que se ofrecian al mismo precio que los destilados de uva de esa época.

Para el caso de la Tacna de hoy, se busca revalorar esta materia prima, los higos secos de la variedad Black mission, para elaborar aguardientes de alta graduación alcohólica, con sus características organolépticas propias y bien apreciadas que permitan mejorar los ingresos familiares de los agricultores de la región.

\section{MATERIALESY MÉTODOS}

\subsection{Descripción del flujo de procesamiento}

a) Recepción. - Para cada una de las tres muestras se pesó $1 \mathrm{~kg}$ de higos y se controló parámetros de humedad, sólidos solubles, acidez total, azúcares reductores y sanidad.

b) Pie de cuba.- Tres días antes de la primera fermentación, se preparó un caldo de cultivo sanitizado y luego sembrado de levaduras vínicas seleccionadas ((30 g/46 kg de fruta).

c) Lavado y trozado.- Los higos secos se lavaron por aspersión con agua corriente, se cortaron sus pedúnculos y fueron trozados en 2 a 3 partes.

d) Encubado y reposo.- Las muestras identificadas como DI:3, D 1:4 y D 1: 5 nos indican la relación higo: agua de cada una.

c) Hidratación y sulfitado-- Se aplicó sanitizante $(20 \mathrm{~g} / \mathrm{HI})$ en el agua para reducir carga microbiana y se dejó hidratar minimo 9 horas hasta estabilizar ganancia de peso en higos.

f) Maceración-Fermentación I, II y III.- Una alícuota $(2.5 \%)$ del pie de cuba fue incorporado $(\mathrm{v} / \mathrm{v})$ a cada muestra para facilitar el arranque de la fermentación I, en condiciones ambientales, que demoró 3 dias, con control de parámetros y corrección de acidez por defecto, luego de lo cual se sustituyó el lote de higos agotados por otro igual, originando la fermentación II que se desarrolló por 5 días, también controlando parámetros y correcciones de proceso. Este procedimiento se repitió una vez más, para generar la fermentación III, que se prolongó por 10 días debido a la creciente concentración de azúcares y al lento trabajo de las levaduras.

g) Descubado y prensado- Los vinos base logrados fueron separados de los higos agotados y las borras formadas mediante operación de sifoneo. A su vez, los higos fueron prensados manualmente con paños sanitizados y estos vinos incorporados al vino base principal. Las borras o lodos restantes fueron descartados.

h) Conservación.- Los vinos base obtenidos fueron estabilizados microbiológicamente con adición de metabisulfito de potasio en dosis equivalente de $20 \mathrm{~g} / \mathrm{HI}$. Se les practicó operaciones de trasiego a los 8,30 y 60 dias posteriores al descube para su estabilización, mejor conservación y homogenización de cualidades físicoquímicas y organolépticas.

i) Destilación. - Usando destiladores de vidrio, de cada muestra de vino base se procedió a obtener las típicas fracciones de "cabeza", "cuerpo" y "cola" controlando temperatura, grado alcohólico, ph, interesando conservar la fracción "cuerpo" de cada destilación.

j) Conservación. - Los destilados o aguardientes de higo fueron puestos en reposo en frascos de vidrio, cerrados, por un mínimo de tres meses.

k) Análisis fisico-quimico y organoléptico.- Cumplido en exceso el tiempo de reposo, las muestras fueron evaluadas por procedimientos fisicos, cromatográficos de gases y organolépticos.

\section{RESULTADOS Y DISCUSIÓN}

3.1. Análisis de la materia prima higo de Magollo Tacna

Ver Tabla 1.

\subsection{Hidratación y sanitización de muestras}

Tras nueve horas de hidratación, en agua sanitizada, las tres muestras, D 1:3, D 1:4 y D 1:5, alcanzaron pesos casi constantes y el incremento fue $67.75 ; 81.75$ y $69.25 \%$ respectivamente.

\subsection{Análisis de los tres procesos de maceración - fermentación sucesivos}

3.3.1 Primera maceración-fermentación.- Tuvo un proceso de tres días y fue casi total la degradación de azúcares por las levaduras, según resultados de densidad, sólidos totales residuales y acidez total.

Tabla 1. Análisis de la materia prima higo de Magollo - Tacna

\begin{tabular}{ccccccccccc}
\hline Comp & Hum. & Prot. & Ceniz & Grasa & Carbo & Fibra & Aci. T & pH & S.S. & Az. R \\
\hline$\%$ & 28.3 & 3.13 & 2.92 & 1.58 & 64.1 & 9.73 & 0.6 & 5.2 & 55.0 & 30.0 \\
\hline
\end{tabular}

Fuente: Elaboración Propia (junio 2009) 
3.3.2 Segunda maceración-fermentación- Con el recambio de higos secos, la maceración fermentación se hizo poco más lenta por el descenso del agua disponible y tras cinco dias, quedaron importantes cantidades de azúcares sin degradar, según se aprecia en resultados. Se tuvieron que hacer correcciones de acidez diarias, 2 y 3 remontajes diarios e incremento artificial de la temperatura ambiental para prevenir paralización de la fermentación.

3.3.3 Tercera maceración - fermentación- Por las mismas anteriores causas, la maceración - fermentación III no se inició pronto debido a la saturación con nuevos azúcares en solución, a la menor disposición de agua en D 1:3 y D 1:4, haciendo mucho más lento el trabajo de las levaduras y este proceso demoró 10 días y aún cuando no se culminó con la esperada degradación de azúcares, se obtuvieron grados alcohólicos bastante elevados en los vinos.

Tabla 2. Control de parámetros al final de la tercera maceración - fermentación

\begin{tabular}{|c|c|c|c|}
\hline Parámetros & D 1:3 & D 1:4 & D 1:5 \\
\hline Tiempo (días) & 10 & 10 & 10 \\
\hline $\begin{array}{l}\text { Densidad corregida } \\
\left(20 / 20^{\circ} \mathrm{C}\right)\end{array}$ & 1.1016 & 1.0597 & 1.0295 \\
\hline $\begin{array}{l}\text { Sólidos solubles } \\
\left({ }^{\circ} \mathrm{Bx}\right)\end{array}$ & 30.0 & 21.5 & 17.0 \\
\hline $\mathrm{pH}$ & 4.2 & 4.1 & 4.2 \\
\hline $\begin{array}{l}\text { Acidez total tartárica } \\
(\mathrm{g} / \mathrm{L})\end{array}$ & 8.32 & 7.125 & 6.225 \\
\hline $\begin{array}{l}\text { Volúmenes de mostos } \\
\text { (L) }\end{array}$ & 1.23 & 2.85 & 3.65 \\
\hline $\begin{array}{l}\text { Temperatura de } \\
\text { mostos }\left({ }^{\circ} \mathrm{C}\right)\end{array}$ & 19.0 & 19.0 & 18.10 \\
\hline $\begin{array}{l}\text { Azúcares reductores } \\
(\%)\end{array}$ & 20.0 & 8.21 & 5.68 \\
\hline $\begin{array}{l}\text { Grado alcohólico ( } \% \\
\text { vol } 20^{\circ} \mathrm{C} \text {.) }\end{array}$ & 22.6 & 24.10 & 24.40 \\
\hline
\end{tabular}

Fuente: Elaboración propia (2009)

\subsection{Evaluaciones físico-químicas de los procesos de destilación}

3.4.1. Corte de "cabeza". - Fueron retirados el $1 \%$ de los volúmenes de los vinos puestos a destilar para obtener grados alcolıólicos $62 ; 60.1$ y $63.2 \%$ vol lo cual es correcto (determinados por picnometria).

3.4.2. Corte de "cuerpo". - las graduaciones alcohólicas de los tres cuerpos tienen valores entre 38 y $40.5 \%$ vol, considerados correctos para ser calificados como aguardientes, aún cuando podrían haber sido un poco más altos de realizarse el corte entre cuerpo y cola, cuando las mezclas hidro alcohólicas marcaban alrededor de $50 \%$ vol.

En la misma tabla apreciamos $\mathrm{pH}$ y los valores de acidez total en términos de $\mathrm{mg} / 100 \mathrm{ml}$ de ácido acético mostrando valores casi diez veces más altos para el primer destilado D 1:3 y casi cinco a seis veces más altos para los destilados D1:4 y D 1:5 si lo comparamos con los valores de un alcohol comercial nacional de $96 \%$ vol que marca $1.80 \mathrm{mg} / 100 \mathrm{ml}$.

Tabla 3. Contenido alcohólico, acidez y pH de los "cuerpos"

\begin{tabular}{llll}
\hline & D 1:3 & D l:4 & D 1:5 \\
\hline Volumen $(\mathrm{ml})$ & 110 & 154 & 176 \\
Alcohol $\left(\%\right.$ vol a $\left.20^{\circ} \mathrm{C}\right)$ & 38,0 & 40,0 & 40,5 \\
Acidez total acética & 17,7 & 9,8 & 10,4 \\
$\mathrm{mg} / 100 \mathrm{ml}$ & 3,6 & 3,8 & 3,7 \\
$\mathrm{pH}$ & & \\
\hline
\end{tabular}

Fuente: Elaboración propia (2010)

\subsection{Evaluación química de la muestra por cromatografía de gases}

Tabla 4. Evaluación química cromatográfica del mejor destilado de higo D1:5

\begin{tabular}{lrr}
\hline Destilado de higo & $\mathrm{Mg} / 100 \mathrm{~mL}$ & $\mathrm{Mg} / 100 \mathrm{~mL} \mathrm{AA}$ \\
\hline Acetato de etilo & 0.77 & 1.92 \\
Metanol & 11.96 & 29.82 \\
2-Propanol & 0 & 0 \\
Isobutanol & 0.9375 & 2.3379 \\
I-Butanol & 0 & 0 \\
Isoamilico & 5.247 & 13.085 \\
Ácido acético & 5.8728 & 14.6453 \\
Furfural & 0.29 & 0.73 \\
\hline
\end{tabular}

Fuente: CERTILAB - Lima (20|0)

Estos resultados son específicos para un destilado de higo (D I:5), influenciado por varios factores como la proporción de higo seco respecto al agua en la maceración - fermentación; a las tres maceraciones fermentaciones consecutivas por 18 dias y al elevado valor residual de azúcares en el vino base puesto a destilar. No se pueden comparar con los valores requisitos para el Pisco (NTP N 211.001 - 2006), pues no lo es; y tampoco se puede comparar con las especificaciones para un aguardiente de caña de azúcar (NTP No211.010-1980) por sus diferentes orígenes. desde la materia prima.

\subsection{Evaluación organoléptica.}

Fue hecha por un panel de cuatro jueces semi entrenados que calificaron, por método hedonistico (de 1 a 9 puntos), el aspecto, color, olor y sabor de los tres destilados resultando la muestra D I:5 como la mejor con 7.70 puntos, calificado entre bueno y muy bueno. Las otras muestras fueron calificadas como regulares con puntajes de 6.68 y 6.37 respectivamente.

\section{CONCLUSIONES}

1. Los higos secos de la var. Black misión tuvieron diferentes tamaños, estados de sanidad y humedades entre 17 y $28.30 \% ; 55^{\circ}$ Brix; azúcares reductores en $30 \%$ y acide $z$ total de $0.6 \%$. 
2. En los procesos de rehidratación de los higos secos que fueron por 9 horas se alcanzaron ganancias de peso de $67.75 ; 81.75$ y $67.48 \%$.

3. Al final de los tres procesos de maceración fermentación sucesivos que demoraron 3, 5 y 10 días, se obtuvieron vinos base con sólidos solubles finales de $30.0 ; 21.5$ y $17.0{ }^{\circ}$ Brix y grados alcohólicos de 22.6; 24.10 y $24.40 \%$ vol respectivamente.

4. Las fracciones "cuerpo" de los tres destilados alcanzaron grados alcohólicos de 38.0; 40.0 y $40.5 \%$ vol medidos a $20^{\circ} \mathrm{C}$.

5. El análisis químico por cromatografia de gases entrega resultados bastante buenos para sus componentes congenéricos, e incluso con valores bajos de acetato de etilo, metanol y furfural.

6. Organolépticamente, la mejor muestra fue el destilado D1:5 que obtuvo calificativo de 7.68 puntos sobre 9.0. En general, los destilados poseen intensos pero volátiles aromas de la materia prima de origen que recuerdan a frutas secas, tonos herbáceos, sabor dulzón inicial, de textura untuosa, y al final dejan un sabor en boca de astringencia y amargor que perduran.

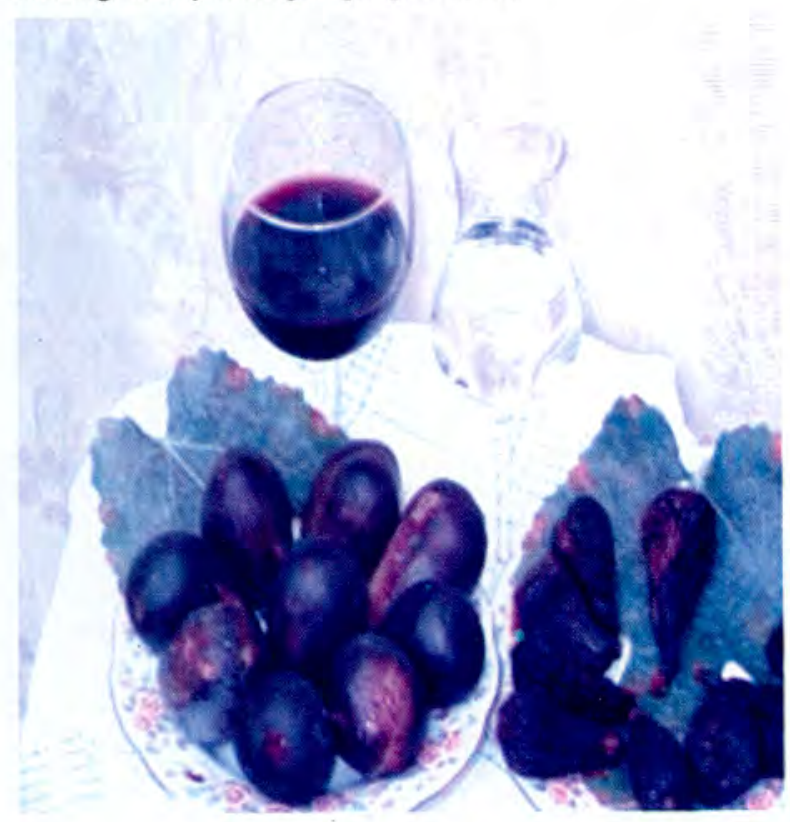

Figura 1. Vino y Destilado de Higos

\section{REFERENCIAS BIBLIOGRÁFICAS}

Colquichagua, Diana; Franco, Ernesto. (1998). Vino de Frutas. Serie de Procesamiento de Alimentos $N^{\circ} 6$. Intermediate Technology Development Group - ITDG. Lima, Perú. Pág 2-32.

De Rivero y Ustereiz, Mariano Eduardo. (1857). Memorias Científicas, Agrícolas e Industriales. Tomo II. Bruselas - Bélgica. Página 229.

Palza Pari, Silvia (2008). Evaluación de Parámetros Tecnológicos en la Obtención de vino a partir de higo (Ficus carica L.) deshidratado, variedad Black Misión. Tesis para obtener el título de Ingeniero en Industrias Alimentarias. UNJBG-Tacna. Páginas 1-31.

Quispe Ascencio, Jorge (2001). Uso del Macerado de Higo (Chimbango) como atrayente en el Control de Caratitis capitala (Wieel) en el Valle de OmateMoquegua. Tesis para optar el grado de Ingeniero Agrónomo. UNJBG-Tacna. Páginas 18-19.

\section{Correspondencia:}

Samuel Cerro Ruiz

Ciudad Universitaria Fundo "Los Granados"

Av. Miraflores s/n. Tacna. Perú

scerro_1@hotmail.com 